\title{
Editorial \\ Novel genetic analysis in Behçet's disease
}

\section{Graham Wallace}

Academic Unit of Ophthalmology, School of Immunity and Infection, University of Birmingham, Vincent Drive, Edgbaston, Birmingham B15 2TT, UK

Corresponding author: Graham Wallace, g.r.wallace@bham.ac.uk

Published: 5 August 2009

Arthritis Research \& Therapy 2009, 11:123 (doi:10.1186/ar2757)

This article is online at http://arthritis-research.com/content/11/4/123

(c) 2009 BioMed Central Ltd

See related research by Fei et al., http://arthritis-research.com/content/11/3/R66

\begin{abstract}
Behçet's disease (BD) is characterized by oral and genital ulceration and is complicated by eye, skin, joint and central nervous system lesions. It has long been understood that BD has a strong genetic component, but to date the identified genes account for only around $30 \%$ of the risk for developing the disease, and the work has mostly been based on candidate gene analysis. In a recent report, Fei and coworkers presented the results of the first genome-wide analysis of patients with BD. These findings suggest new pathways for investigation in this complex disease.
\end{abstract}

Error, like straws, upon the surface flow He who would search for pearls must dive below

John Dryden, 1678

Fei and coworkers [1] identified novel single nucleotide polymorphisms (SNPs) in five genes (KIAA1529, CPVL, $\angle O C 100129342, U B A S H 3 B$ and UBAC2) that encode proteins with both known and unknown functions. Moreover, subset analysis showed links between some of the SNPs and particular manifestations of Behçet's disease (BD).

KIAA1529 and LOC100129342 have no known function, but the latter SNP on chromosome 1p34 confirms a locus previously identified in a multiplex family study [2]. UBASH3B and UBAC2 encode ubiquitin-associated proteins. The ubiquitin system is best described in targeting misfolded or damaged proteins for proteosomal degradation, but it is also involved in several other cellular processes, including regulation of nuclear factor- $\mathrm{KB}$ function and autophagy. Such processes are involved in cells of both innate and adaptive immune responses, which is of interest with respect to the ongoing debate on whether BD is an autoinflammatory or an autoimmune disorder [3]. Dysfunction of the ubiquitin pathway has been implicated in cancer, neurodegenerative diseases and type 2 diabetes $[4,5]$.
Carboxypeptidase vitellogenic-like protein is upregulated in monocytes on conversion to macrophages, in which it colocalizes to the secreted proteins tumour necrosis factor and the chemokine CCL3 (C-C chemokine ligand 3 ). It has been implicated in the processing/transport of peptides for loading onto major histocompatibility complex (MHC) class I molecules [6]. The strongest genetic association with $\mathrm{BD}$ is human leucocyte antigen (HLA)-B`5101 and HLA-B ${ }^{\star} 5108$, an $\mathrm{MHC}$ class I molecule. Microsatellite analysis confirms HLA-B85101/5108 as the most likely causative gene in BD, but SNPs in other genes in close proximity on chromosome 6 MICA, MICB and TNF - have also been reported [7]. Moreover, the mechanism of action of HLA-B ${ }^{\star} 5101 / 5108$ in BD has not been elucidated. Alteration in the process of peptide production by the CVLP SNP could have important implications in the expression or maintenance of MHC class I molecules on the cell surface and be linked to the pathogenesis of the disease.

In subset analysis the UBASH3B SNP was more common in patients with ocular and vascular manifestations, whereas the KIAA1529 SNP was more common in patients without such involvement. The authors correctly stated that the numbers with each manifestation make such an analysis very preliminary, but several other SNPs have been linked to ocular disease specifically, so these findings are not unexpected [8]. It should be noted, however, that eye and vascular disease can take many forms in $\mathrm{BD}$, and more detailed analysis will be required when greater numbers are tested for these SNPs.

There are certain caveats to the findings. Genome-wide analysis (GWAS) is normally performed on a large number of samples, which is not easy for a rare condition such as BD. The authors addressed this point by performing the initial analysis on pooled samples and then, having identified potential SNPs, validating the findings in each sample

$\mathrm{BD}=$ Behçet's disease; GWAS = genome-wide analysis; HLA = human leucocyte antigen; $\mathrm{MHC}=$ major histocompatibility complex; SNP = single nucleotide polymorphism. 
individually. However, it is important for these results to be validated in other cohorts of BD patients. There are extensive data describing ethnic differences in SNPs studied by candidate analysis, and the association of these newly identified SNPS in BD patients from different geographical areas will be important. Similarly, in several studies males have been shown to have a worse prognosis, and the association of these SNPs with sex should be examined. Other GWAS are ongoing or planned in Japanese, European and Turkish patients with BD, and comparison with the current study will be of great interest. Finally, and most importantly, the functional relevance of these SNPs will need to be investigated and - if found - tested in different cell types such as lymphoid, myeloid, epithelial and endothelial cells that are involved in BD.

BD is a complex disease. Different patients will experience different symptoms, and there is a clear geographical distribution of the disease. The candidate gene approach has been useful in identifying susceptibility and severity genes in $\mathrm{BD}$, but the ability to undertake GWAS has led to the identification of several new SNPs in many human diseases, increasing our understanding of the pathogenic mechanisms involved. Fei and coworkers [1] are to be commended for such a study in BD.

\section{Competing interests}

The author declares that they have no competing interests.

\section{References}

1. Fei $Y$, Webb R, Cobb B, Direskeneli H, Saruhan-Direskeneli G, Sawalha AH: Identification of novel genetic susceptibility loci for Behçet's disease using a genome-wide association study. Arthritis Res Ther 2009, 11:R66.

2. Karasneh J, Gul A, Ollier WE, Silman AJ, Worthington J: Whole genome screening for susceptibility genes in multicase families with Behcet's disease. Rheumatology (Oxford) 2005, 52: 1836-1842.

3. Direskeneli $\mathrm{H}$ : Autoimmunity vs autoinflammation in Behcet's disease: do we oversimplify a complex disorder? Rheumato/ogy (Oxford) 2006, 45:1461-1465.

4. Bhoj VG, Chen ZJ: Ubiquitylation in innate and adaptive immunity. Nature 2009, 458:430-437.

5. Hoeller D, Dikic I: Targeting the ubiquitin system in cancer therapy. Nature 2009, 458:438-444.

6. Harris J, Schwinn N, Mahoney JA, Lin HH, Shaw M, Howard CJ, da Silva RP, Gordon S: A vitellogenic-like carboxypeptidase expressed by human macrophages is localized in endoplasmic reticulum and membrane ruffles. Int J Exp Pathol 2006, 87:29-39.

7. Deucher CM, Kotter I, Wallace GR, Murray PI, Stubinger N, Zierhut M: Behcet's disease: ocular effects and treatment. Prog Retin Eye Res 2008, 27:111-136.

8. Verity DH, Vaughan RW, Madanat W, Kondeatis E, Zuriekat $H$, Fayyad F, Kanawati CA, Ayesh I, Stanford MR, Wallace GR: Factor $\mathbf{V}$ Leiden mutation is associated with ocular involvement in Behcet's disease. Am J Ophthalmol 1999, 128:352356. 